\title{
MARICULTURA SUSTENTÁVEL NO LITORAL DO PARANÁ, BRASIL: atualidades e perspectivas
}

\author{
Sustainable mariculture in Paraná coast, Brazil: updates and perspectives
}

\author{
Ana Paula Baldan ${ }^{[a]}$, Fabiano Bendhack ${ }^{[b]}$ \\ [a] Zootecnista, Doutora, Pesquisadora do Centro de Produção e Propagação de Organismos Marinhos - CPPOM PUCPR, \\ Guaratuba, PR - Brasil, e-mail: ana.baldan@pucpr.br \\ ${ }^{[b]}$ Zootecnista, Doutor, Pesquisador do Centro de Produção e Propagação de Organismos Marinhos - CPPOM PUCPR, \\ Guaratuba, PR - Brasil, e-mail: f.bendhack@pucpr.br
}

\begin{abstract}
Resumo
A pesca vem apresentando dados de estabilização nas taxas de captura em todo o mundo, apesar do aumento do esforço com desenvolvimento de tecnologias. Essa tendência tem levado o pescador artesanal a buscar outras opções de sustento. Este artigo apresenta a maricultura destacando espécies nativas como a ostra (Crassostrea sp.) e o robalo peva (Centropomus parallelus). O cultivo dessas espécies é uma alternativa de atividade sustentável em ambientes estuarinos, onde é realizada a maior parte da pesca artesanal. São apresentados exemplos de cultivos produtivos e experimentais das espécies adaptadas ao ambiente estuarino e que apresentam demanda pelo consumidor, habituado a adquirir esses produtos.
\end{abstract}

Palavras-chave: Maricultura. Ostra nativa. Robalo peva. Paraná.

\begin{abstract}
Fisheries have showed stabilized data of capture rates in the world, despite of the increased effort in technologies development. This tendency has led the artisanal fishermen to look for other options for sustenance. This paper presents the mariculture, highlighting the native species as the Brazilian mangrove oyster (Crassostrea sp.) and the fat snook (Centropomus parallelus). The cultivation of these species are an alternative of sustainable activity in estuary environments, where is performed most of the artisanal fishing. We present examples of productive and experimental cultures of estuarine species adapted and the demand for consumer, used to purchase these products.
\end{abstract}

Keywords: Mariculture. Native oyster. Fat snook. Paraná.

Rev. Acad., Ciênc. Agrár. Ambient., Curitiba, v. 7, n. 4, p. 491-497, out./dez. 2009 


\section{INTRODUÇÃO}

O aumento da tecnologia de pesca e esforço exercido nos estoques pesqueiros naturais não tem mudado o panorama mundial do volume de pescado capturado, que se encontra relativamente estabilizado. Em contrapartida, a produção aquícola representada por peixes, crustáceos, moluscos e outros animais aquáticos produzidos continua a crescer com uma taxa média anual de 8,8\% desde 1970, em comparação com apenas $1,2 \%$ para a pesca e $2,8 \%$ para a produção agropecuária terrestre (FAO, 2009).

A maior parte dessa produção aquícola mundial é predominante de espécies cultivadas em água doce (56,6\% em quantidade e 50,1\% em termos de valor). Já a maricultura, representada pelas espécies cultivadas em água salgada, contribui com 36\% da produção em quantidade e 33,6\% do valor total. Os cultivos em água salobra, apesar de representarem apenas 7,4\% do total produzido pela aquicultura em 2004, contribuíram com 16,3\% do valor total produzido, devido ao alto valor das espécies de peixes e camarões produzidos nesses ambientes (FAO, 2009).

Estatísticas pesqueiras realizadas na Flórida, EUA, mostram que 80\% das espécies com interesse comercial ou recreacional daquela região têm dependência obrigatória dos estuários ao menos em uma fase de sua vida (HAMILTON; SNEDAKER, 1984). A elevada demanda de recursos provenientes dos estuários em todo o mundo, aliada à escassez desse pescado, ocasiona uma elevação em seu valor.

As características geográficas, culturais e biológicas do litoral paranaense fazem dele um ambiente muito propício ao desenvolvimento da maricultura como forma de sustento econômico das famílias e de preservação do ambiente estuarino. Este artigo tem como objetivo apresentar as situações atuais e perspectivas para o desenvolvimento sustentável da produção de ostra nativa (Crassostrea sp.) e do robalo peva (Centropomus parallelus) no litoral paranaense.

\section{Litoral do Paraná}

A costa paranaense possui $126 \mathrm{~km}$ de extensão linear no sentido norte-sul, constituindo um dos menores litorais entre os Estados litorâneos brasileiros (ÂNGULO et al., 1996). Apesar disso, se forem consideradas as reentrâncias, estuários e ilhas, a linha de costa ultrapassa centenas de quilômetros.

A Baía de Guaratuba, no extremo sul da zona costeira, é independente e consideravelmente menor e mais rasa do que a de Paranaguá, adentrando menos de $15 \mathrm{~km}$ no continente. A Baía de Paranaguá constitui um grande e complexo sistema estuarino com diversos corpos d'água interconectados. Esse estuário se compõe das baías de Paranaguá e Antonina com orientação leste-oeste, $50 \mathrm{~km}$ de extensão com largura máxima de $7 \mathrm{~km}$ e área de $260 \mathrm{~km}^{2}$. No mesmo complexo estão as baías de Guaraqueçaba, Laranjeiras e Pinheiros, com orientação norte-sul, cerca de $30 \mathrm{~km}$ de comprimento, 13 $\mathrm{km}$ de largura e área de $200 \mathrm{~km}^{2}$ (ANDRIGUETTO FILHO et al., 2006).

Tradicionalmente, na maior parte das regiões do litoral do Estado do Paraná a pesca artesanal apresenta-se como principal fonte de renda das comunidades, porém nos últimos anos revelou um processo acentuado de declínio da atividade (CHAVES et al., 2002).

\section{O cultivo de ostras no litoral do Paraná}

Atualmente, grande parte das ostras comercializadas no litoral do Paraná ainda é proveniente do extrativismo. Sementes extraídas de bancos naturais são colocadas em estruturas de cultivo ou diretamente no lodo para terminarem seu desenvolvimento. Outra forma para comercialização das ostras é a coleta de animais já em fase adulta. Como consequência, esses fatos apontam para uma diminuição nos bancos naturais de ostras (ABSHER; CALDEIRA, 2007). Por outro lado, a atividade é uma das formas que garantem uma renda complementar para muitas famílias do litoral.

As ostras comercializadas e/ou consumidas pela população local são conhecidas popularmente como ostra-da-pedra, ostra-do-mangue e ostra-de-fundo. Pesquisas confirmam a presença de duas

Rev. Acad., Ciênc. Agrár. Ambient., Curitiba, v. 7, n. 4, p. 491-497, out./dez. 2009 
espécies de ostras através de análise genética: a Crassostrea rbizophorae e a C. brasiliana (IGNÁCIO et al., 2000). Essas espécies são adaptadas à zona estuarina, região que apresenta variações ambientais com ocorrências de baixas salinidades em períodos chuvosos e altas temperaturas durante o verão.

A C. rbizophorae, ou ostra-da-pedra, está presente normalmente fixada nas raízes aéreas de plantas do mangue, em regiões entre-marés e pode atingir até $10 \mathrm{~cm}$ de altura. A espécie $C$. brasiliana, ou ostra de fundo, ocorre em região permanentemente submersa e é considerada uma espécie de grande porte, podendo atingir mais de $20 \mathrm{~cm}$ de altura (CHRISTO, 2006). Os adultos de ambas as espécies são sésseis, caracterizados por apresentarem grande plasticidade na morfologia da concha, dependendo do substrato onde estão fixadas (ABSHER, 1989), de forma que sua coleta no ambiente pode gerar controvérsias na identificação.

No Brasil, a produção de sementes em laboratório ainda é muito pequena. A principal espécie produzida é a ostra-do-pacífico (Crassostrea gigas), introduzida na década de 70. A ostra-dopacífico representa $90 \%$ da produção nacional de moluscos, concentrando-se no Estado de Santa Catarina, onde essa espécie teve melhor adaptação.

A produção da ostra nativa há pouco tempo dependia exclusivamente de sementes dos bancos naturais para cultivo e comercialização, o que não garante a sustentabilidade da atividade e regularidade no comércio desses animais. A aquisição de sementes produzidas em laboratório é o principal fator para o desenvolvimento sustentável dos cultivos de ostras. Além de não causar impacto nos bancos naturais, as sementes produzidas em laboratório já são selecionadas, garantindo ao produtor maior qualidade e regularidade na produção (BALDAN et al., 2009).

Segundo Suplicy (2008), apenas dois laboratórios de bivalves existiam no país: o primeiro é o Laboratório de Moluscos Marinhos (LMM), da Universidade Federal de Santa Catarina (UFSC), localizado em Florianópolis, sendo a ostra-do-pacífico (Crassostrea gigas) a principal espécie produzida. A produção é comercializada principalmente entre os produtores do Estado de Santa Catarina, e as sementes são de ostras nativas (C. brasiliana e C. rbizophorae), produzidas apenas em escala experimental. O segundo é o Instituto de Ecodesenvolvimento da Baía de Ilha Grande (IED-BIG), cujo laboratório de produção de sementes de bivalves localiza-se em Angra dos Reis, Rio de Janeiro. No entanto, o principal molusco produzido nesse laboratório é de sementes de vieiras (Nodipetcen nodosus) que também são vendidas principalmente para os produtores locais.

Suplicy (2008) ainda relata um terceiro laboratório prestes a iniciar a produção de ostras nativas, no Estado do Rio Grande do Norte. O abastecimento regional é ansiosamente aguardado por um número de produtores que dependem da coleta de sementes na natureza.

No Paraná, há também grande demanda por sementes produzidas em laboratório. No complexo estuarino de Paranaguá, em 13 parques ostreícolas, Europinha, Medeiros, Almeida, Ilha Rasa, Ponta do Lanço, Guapicum, Vila das Peças, Tibicanga, Poruquara, Canudal, Sebuí, Vila Fátima e Barbados, foram identificadas 452 famílias residentes nessas comunidades envolvidas com a atividade da produção de ostras. A maioria desses produtores obtinha sementes por extração dos bancos naturais (ABSHER; CALDEIRA, 2007).

O Centro de Produção e Propagação de Organismos Marinhos, da Universidade Católica do Paraná (CPPOM-PUCPR), localizado em Guaratuba, desenvolveu a tecnologia de produção e iniciou em 2009 o fornecimento de sementes de ostra nativa em larga escala. A produção de sementes objetivou capacitar produtores a cultivarem ostras a partir de sementes de laboratório. Resultados preliminares apontaram o bom desempenho produtivo da ostra nativa, porém algumas necessidades foram verificadas, como: adaptar equipamentos a essa espécie, testar diferentes sistemas de cultivo, fixos (mesas) e flutuantes (long line) e selecionar alguns produtores a trabalharem com a recria de sementes.

Outra questão importante no desenvolvimento da cadeia produtiva da ostra nativa é a comercialização. A maior parte da produção é comercializada in natura por famílias de pescadores artesanais ou pequenos produtores. O problema de comercialização de bivalves cultivados na América Latina está relacionado principalmente à desconfiança que existe do consumidor sobre o estado sanitário desses produtos, refletindo um baixo consumo (URIARTE et al., 2008).

A depuração desses moluscos por no mínimo 6 horas, em tanques com água devidamente tratada por filtração e esterilização, garantem a eliminação de substâncias retidas nos tecidos das ostras,

Rev. Acad., Ciênc. Agrár. Ambient., Curitiba, v. 7, n. 4, p. 491-497, out./dez. 2009 
tornando-as aptas para o consumo do ponto de vista microbiológico, pois elimina a maior parte dos organismos patogênicos (MACHADO et al., 2002). Nesse sentido foram instaladas unidades de depuração nos municípios litorâneos do Estado do Paraná. As técnicas de operação dessas unidades estão em desenvolvimento. No município de Guaratuba, a unidade de depuração já se encontra em funcionamento com assistência técnica do Instituto Emater, que atua também no desenvolvimento da maricultura com a elaboração dos projetos técnicos e de licenciamento das áreas de cultivo no Estado.

\section{O cultivo de robalo (Centropomus parallelus) nos estuários paranaenses}

A piscicultura marinha no Brasil ocorre em escala experimental, principalmente com estudos sobre reprodução, larvicultura e alimentação, ou em cultivos para sustento próprio com a estocagem de peixes capturados na natureza. No País, o desenvolvimento de tecnologia para a engorda está iniciando, sendo que a maioria das técnicas disseminadas são modelos desenvolvidos no exterior com baixa reprodutibilidade regional.

O Bijupirá (Racbycentron canadum) é uma das espécies que vem apresentando crescimento acelerado em cultivos asiáticos e hoje é preconizado como uma espécie para o desenvolvimento industrial da piscicultura marinha no Brasil, porém não viável economicamente para incentivar os pescadores artesanais e a aquicultura familiar (SANCHES et al., 2008).

Já o robalo peva (Centropomus parallelus) é uma espécie estuarina nativa, popularmente conhecida em todo o litoral do país e possui mercado consumidor consolidado. O robalo ainda possui diversas características adequadas para a produção, como: facilidade na adaptação ao cativeiro devido ao hábito gregário, Tolerância a altas densidades, resistência à eutrofização (CERQUEIRA, 2005) e variações de salinidade da água (TSUZUKI et al., 2007). Seu valor no mercado é o mais alto, entre peixes de água doce e marinhos (CEAGESP, 2009). Essas características biológicas, produtivas e de mercado do robalo peva permitem apontá-lo como uma espécie altamente recomendada para famílias de maricultores instalarem cultivos em regiões estuarinas, como é a maior parte do litoral do Estado do Paraná.

Essa possibilidade tem levado a intensificação dos estudos sobre sua biologia e o desenvolvimento de técnicas de reprodução e cultivo de juvenis de robalo. No Brasil, o robalo é uma das poucas espécies de peixes marinhos que possuem pesquisas sobre tecnologia produtiva. Mesmo assim, a maior parte dos estudos é referente à reprodução e larvicultura (CERQUEIRA; BERNARDINI, 1995; GODINHO et al., 2000; SEIFFERT et al., 2001; ALVAREZ-LAJONCHËRE et al., 2002; CERQUEIRA, 2002; REIS et al., 2003; TEMPLE et al., 2004).

A reprodução e larvicultura de robalos em larga escala foram iniciadas no país pelo Laboratório de Piscicultura Marinha da Universidade Federal de Santa Catarina (CERQUEIRA, 1991). Em 2006, o CPPOMPUCPR iniciou a produção de alevinos no Estado do Paraná, com a finalidade inicial de repovoamento, e hoje atua com pesquisas relacionadas ao cultivo da espécie em tanques-rede na Baía de Guaratuba.

Apesar de existirem cultivos experimentais com robalo peva (OSTINI et al., 2007; TSUZUKI et al., 2008), há poucas pesquisas relacionadas a aspectos nutricionais da espécie. A inexistência de dietas comerciais para peixes marinhos no país levam à utilização de rações comerciais formuladas para outras espécies, como, por exemplo, rações para trutas ou camarões. Esses estudos promovem um bom conhecimento do comportamento alimentar da espécie, porém pesquisas precisam ser desenvolvidas para expressar o total desempenho do robalo peva com dietas específicas.

Outro obstáculo para o cultivo de peixes marinhos é a necessidade de desenvolvimento de estruturas de baixo custo que permitam o cultivo em tanques-rede de pequeno volume, com resistência ao ambiente marinho, como forças de marés e a agressividade da oxidação do sal.

\section{Desafios e perspectivas}

Ao contrário do verificado em experiências negativas para os ambientes estuarinos em várias partes do mundo, as atividades da aquicultura e manguezais não são necessariamente incompatíveis.

Rev. Acad., Ciênc. Agrár. Ambient., Curitiba, v. 7, n. 4, p. 491-497, out./dez. 2009 
Cultivos de ostras e peixes em gaiolas em âmbito familiar, por exemplo, são operações que convivem com os ambientes de estuários. As principais características que levam a essa constatação é que para essas culturas o desmatamento é desnecessário, e a qualidade da água nas adjacências das áreas de cultivo é fator indispensável para a sustentabilidade da cultura (WALTERS et al., 2008). Além disso, ações ecologicamente prejudiciais precisam ser substituídas por boas práticas de cultivo, tais como instalação de tanques e estruturas de cultivo fora das matas de manguezais, utilização de espécies nativas (cujos inevitáveis escapes seriam relativamente inócuos), além dos alevinos e do uso de sementes oriundas de Unidades de Reprodução em Cativeiro e não coletadas da natureza (PRIMAVERA, 2005).

A introdução da aquicultura nas comunidades de pescadores artesanais representa potencial para promoção do desenvolvimento econômico (CHAVES et al., 2002). Essa inserção torna possível ao pescador artesanal atuar em uma atividade ligada às suas origens. As áreas do litoral do Paraná, como o complexo estuarino de Paranaguá e a Baía de Guaratuba, podem ser utilizadas para cultivos de espécies aquáticas de forma a compatibilizar a renda dos pescadores com o equilíbrio ambiental.

Os organismos marinhos nativos possuem elevado potencial para cultivos, principalmente pela alta demanda pelo consumidor habituado a adquirir os mesmos produtos de origem pesqueira. Entretanto o desenvolvimento de tecnologia de produção é lento e muitas vezes substituído pela introdução de espécies exóticas com técnicas estabelecidas. $\mathrm{Na}$ maior parte das vezes, em curto prazo, as culturas estabelecidas dessas espécies se apresentam como solução ideal para garantir a escassez do pescado, porém dificuldades antes não previstas surgem durante o cultivo, como baixa resistência a variações climáticas e aos parasitas, além de dificuldades de comercialização de um produto ainda desconhecido.

\section{CONSIDERAÇÕES FINAIS}

Atualmente pesquisas relacionadas à reprodução de espécies nativas e técnicas de cultivo e depuração vêm sendo aprimoradas e transferidas para os maricultores do litoral paranaense. Para a consolidação e crescimento da maricultura nos estuários, o aperfeiçoamento dessas tecnologias de produção de espécies nativas com cultivos em âmbito familiar e capacitação técnica e empreendedora aos maricultores são necessários para o desenvolvimento sustentável da atividade.

\section{AGRADECIMENTOS}

Os autores agradecem o apoio financeiro da Secretaria de Ciência, Tecnologia e Ensino Superior do Estado do Paraná para o desenvolvimento dos projetos realizados no CPPOM-PUCPR, Conv. 022/03 e 023/03, e à Prefeitura Municipal de Guaratuba, pelo Conv. PMG-PUCPR/99.

\section{REFERÊNCIAS}

ABSHER, T. M. Populações naturais de ostras do gênero Crassostrea do litoral do Paraná: desenvolvimento larval, recrutamento e crescimento. 1989. 185 f. Tese (Doutorado em Oceanografia) - Universidade de São Paulo, Instituto Oceanográfico, 1989.

ABSHER, T. M.; CALDEIRA, G. A. Caracterização dos parques de cultivo de ostras do litoral do Paraná: aspectos técnico-produtivos e sócio econômicos. In: BARROSO, G. F.; POERSCH, L. H. S.; CAVALLI, R. O. (Org.). Sistemas de cultivos aquícolas costeiros no Brasil: recursos, tecnologias e aspectos ambientais e sócio-econômicos. Rio de Janeiro: Museu Nacional, 2007. p. 181-192.

ALVAREZ-LAJONCHERE, L. S. et al. Mass production of juveniles of the fat snook Centropomus parallelus in Brazil. Journal of the World Aquaculture Society, Baton Rouge, v. 33, n. 4, p. 506516, 2002.

Rev. Acad., Ciênc. Agrár. Ambient., Curitiba, v. 7, n. 4, p. 491-497, out./dez. 2009 
ANDRIGUETTO FILHO, J. M. et. al. Diagnóstico da pesca no litoral do estado do Paraná. In: ISAAC, V. J. et al. (Org.). A pesca marinha e estuarina do Brasil no início do século XXI: recursos, tecnologias, aspectos socioeconômicos e institucionais. Belém: UFPA, 2006. p. 117-140.

ANGULO, R. J. et al. Classificação da costa paranaense com base na sua dinâmica, como subsídio à ocupação da orla litorânea. Boletim Paranaense de Geociências, Curitiba, v. 44, p.7-17, 1996.

BALDAN, A. P. et al. Criação de ostras nativas. Curitiba: Emater/PR, 2009.

CEAGESP. Cotação de preços no atacado. São Paulo. Disponível em: < http://www.ceagesp.gov.br/ cotacoes/index_html?b_start:int $=0 \&$ grupo_nome $=$ Pescado\&consultar $=$ Consultar\&grupo $=6 \& d a t a=10 /$ 09/2009>. Acesso em: 10 set. 2009.

CERQUEIRA, V. R. Cultivo do robalo-peva, Centropomus parallelus. In: BALDISSEROTTO, B.; GOMES, L. C. (Org.). Espécies nativas para piscicultura no Brasil. Santa Maria: UFSM, 2005. p. 403-431.

CERQUEIRA, V. R. Cultivo do robalo: aspectos da reprodução, larvicultura e engorda. Florianópolis: Ed. da UFSC, 2002.

CERQUEIRA, V. R. Testes de indução de desova do robalo, Centropomus parallelus, do litoral da ilha de Santa Catarina com gonadotrofina cariônica humana (HCG). In: CONGRESSO BRASILEIRO DE ENGENHARIA DE PESCA, 7., 1995, SANTOS. Anais... Santos: Associação dos Engenheiros de Pesca de PE, 1991. p. 95-102.

CERQUEIRA, V. R.; BERNARDINI, M. E. The weaning of the fat snook Centropomus parallelus larvae with experimental and commercial artificial diets. In: LARVI '95 - FISH \& CRUSTACEAN LARVICULTURE SYMPOSIUM, 24., 1995. Gent. Proceedings... Gent: European Aquaculture Society Special Publication, 1995. p. 272-275.

CHAVES, P. et al. Biological, technical and socioeconomic aspects of the fishing activity in a Brazilian estuary. Journal of Fish Biology, London, v. 61, (Supplement A), p. 52-59, 2002.

CHRISTO, S. W. Biologia Reprodutiva e Ecologia de Ostras do Gênero Crassostrea sacco, 1897 na Baía de Guaratuba (Paraná - Brasil): um subsídio do cultivo. 2006. 146 f. Tese (Doutorado em Ciências, Zoologia) - Universidade Federal do Paraná, Curitiba, 2003.

FOOD AND AGRICULTURE ORGANIZATION - FAO. The state of world fisheries and aquaculture (SOFIA) 2008. Rome: Fisheries and Aquaculture Department of Food and Agriculture Organization of the United Nations, 2009.

GODINHO, H. M. et al. Reprodução induzida em robalo Centropomus parallelus Poey, 1860. Brazilian Journal of Veterinary Research and Animal Science, São Paulo, v. 37, n. 1, p. 1-10, 2000.

HAMILTON, L. S.; SNEDAKER, S. C. Handbook for mangrove area management. Honolulu: United Nations Environment Program - East-West Center, 1984.

IGNÁCIO, B. L. et al. Genetic evidence of the presence of two species of Crassostrea (Bivalvia: Ostreidae) on the coast of Brazil. Marine Biology, Berlin, v. 136, n. 6, p. 987-991, 2000.

MACHADO, I. C. et al. Obtenção de parâmetros para a depuração da ostra de mangue Crassostrea brasiliana em Cananéia, SP. In: SIMPÓSIO BRASILEIRO DE AQÜICULTURA, 12., 2002, Goiânia. Anais... Goiânia: UFG, 2002. p. 12.

OSTINI, S. et al. Criação do robalo-peva (Centropomus parallelus) submetido a diferentes densidades de estocagem. Revista Brasileira de Saúde e Produção Animal, Salvador, v. 8, n. 3, p. 250-257, 2007. 
PRIMAVERA, J. H. Mangroves, fishponds, and the quest for sustainability. Science, Washington, v. 310, n. 5.745 , p. $57-59,2005$.

REIS, M. A. et al. Indução de desova do robalo-peva Centropomus parallelus Poey 1860, com diferentes doses de LHRHa. Acta Scientiarum, Maringá, v. 25, n. 1, p. 53-59, 2003.

SANCHES, E. G. et al. Viabilidade econômica do cultivo do bijupirá (Rachycentron canadum) em sistema offshore. Informações Econômicas, São Paulo, v. 38, n. 12, p. 42-41, 2008.

SEIFFERT, M. B. et al. Effect of dietary (n-3) highly unsaturated fatty acids (HUFA) on growth and survival of fat snook (Centropomus parallelus, Pisces: Centropomidae) larvae during first feeding. Brazilian Journal of Medical and Biological Research, Ribeirão Preto, v. 34, n. 5, p. 645-651, 2001.

SUPLICY, F. M. Legal aspects and governmental actions for the development of mollusc farming in Brazil. In: LOVATELLI, A.; FARIAS, A.; URIARTE, I. (Org.). Estado actual del cultivo y manejo de moluscos bivalvos y su proyección futura: factores que afectan su sustentabilidad em América Latina. Roma: Food and Agriculture Organization, 2008. v. 12. p. 205-208.

TEMPLE, S. et al. The effects of lowering prey density on the growth, survival and foraging behaviour of larval fat snook (Centropomus parallelus Poey 1860). Aquaculture, Amsterdam, v. 233, n. 1/4, p. 205-217, 2004.

TSUZUKI, M. Y. et al. Survival, growth and digestive enzyme activity of juveniles of the fat snook (Centropomus parallelus) reared at different salinities. Aquaculture, Amsterdam, v. 271, p. 319-325, 2007.

TSUZUKI, M. Y. et al. Desempenho de juvenis de robalo-peva Centropomus parallelus com diferentes dietas comerciais e freqüências alimentares. Boletim do Instituto de Pesca, São Paulo, v. 34, p. 535-541, 2008.

URIARTE, I. et al. Cultivo y manejo de moluscos bivalvos en América Latina: resultados y conclusiones del primer taller. In: LOVATELLI, A.; FARÍAS, A.; URIARTE, I. (Org.). Estado actual del cultivo y manejo de moluscos bivalvos y su proyección futura: factores que afectan su sustentabilidad en América Latina. Roma: Food and Agriculture Organization, 2008. v. 12. p. 1-43.

WALTERS, B. B. et al. Ethnobiology, socio-economic and management of mangrove forests: a review. Aquatic Botany, Elsevier, v. 89, p. 220-236, 2008.

Recebido: 02/09/2009

Received: 09/02/2009

Aprovado: 15/09/2009

Approved: 09/15/2009 